between 30 and 50 years. There was no familial tendency in the patient's family.

While cases like this are admittedly rare, there is the probability of misdiagnosis in some areas, where the physicians are not aware of its mode of presentation and where there are no facilities for adequate investigations. Such cases very often can be mistaken for miliary tuberculosis and the patients placed unnecessarily on anti-tuberculosis therapy. However, the exercise tolerance of the patient, the continued absence of tubercle bacilli from the sputum, the discrepancy between the mild clinical symptoms and the high degree of radiographic opacity should exclude severe tuberculosis. The absence of iron from the sections of the lungs in this case, the miliary pattern, which fell into a different category from those of haemosiderotic lungs, described by Laubry and Abbas (1948) and Lendrum, Scott and Park (1950) and the relative freedom of the patient from recurrent attacks of dyspnoea and cyanosis may help to exclude haemosiderosis. The clinical history and the extent and pattern of distribution of the pulmonary opacities are likely to distinguish such diseases as silicosis, histoplasmosis and schistosomiasis.

\section{Acknowledgments}

We are grateful to Mr J. A. Ogunremi of the Department of Pathology for the photomicrograph, the Staff of the Medical Illustration Unit for the illustrations, and to Mr Patrick D. Saduwa for secretarial assistance.

\section{References}

Abdel-Hakim, M., Elmallah, S., Hashem, S. \& AbdelHalim, S. (1959) Pulmonary alveolar microlithiasis. Thorax, 14, 263.

Badger, T.L., Gottliers, L. \& Gaensler, E.A. (1955) Pulmonary alveolar microlithiasis or calcinosis of the lungs. New England Journal of Medicine, 253, 709.

Chinachoti, N. \& Tangchai, P. (1957) Pulmonary alveolar microlithiasis. Diseases of the Chest, 32, 687.

FinkbINer, R.B., DeCKer, J.P. \& CoOPER, D.A. (1957) Pulmonary alveolar microlithiasis. American Review of Tuberculosis and Pulmonary Diseases, 75, 122.

Friedreich, N. (1856) Corpora amylaea in den Lungen. Virchows Archiv für pathologische Anatomie und Physiologie und für klinische Medizin, 10, 507.

GreenberG, M.S. (1957) Miliary shadows in the lungs due to microlithiasis alveolaris pulmonum. Thorax, 12, 171.

Kent, G., Gilbert, E.S. \& Meyer, H.H. (1955) Pulmonary microlithiasis. A.M.A. Archives of Pathology, 60, 556.

LAUBRY, L. \& ABAS, L. (1948) Les ombres radiologiques pulmonaires, du type micronodulaires, chez les cardiaques: l'hémosidérose pulmonaire. Acta cardiologica, 3, 91.

Lendrum, A.C., Scotr, L.D.W. \& PARK, S.D.S. (1950) Pulmonary changes due to cardiac disease with special reference to haemosiderosis. Quarterly Journal of Medicine, 43, 249.

PuHr, L. (1933) Mikrolithiasis alveolaris pulmonum. Virchows Archiv für pathologische Anatomie und Physiologie und für klinische Medizin, 290, 156.

Sharp, M.E. \& Danino, E.A. (1953) An unusual form of pulmonary calcification: microlithiasis alveolaris pulmonum. Journal of Pathology and Bacteriology, 65, 389.

Sosman, M.C., Dodd, G.D., Jones, W.D. \& Pillmore, G.U. (1957) The familial occurrence of pulmonary alveolar microlithiasis. American Journal of Roentgenology, 77, 947.

ViswanATHAM, R. (1962) Pulmonary alveolar microlithiasis. Thorax, 17, 251.

\title{
Paravertebral and peripheral ligamentous ossification: an unusual association of hypoparathyroidism
}

\author{
J. E. AdAms \\ M.B., B.S., M.R.C.P., D.M.R.D., F.R.C.R.
}

M. DAVIES

M.B., B S., M.R.C.P.

Departments of Metabolism and Medicine, and Radiodiagnosis, Manchester Royal Infirmary

\begin{abstract}
Summary
A 62-year-old man with idiopathic hypoparathyroidism and extensive paravertebral and ligamentous ossification is reported. The clinical and radiological findings of this, and other reported cases, are discussed and compared with other causes of paravertebral ossification.
\end{abstract}

Correspondence: Dr J. E. Adams, Department of Radiology, Manchester Royal Infirmary, Oxford Road, Manchester M13 9WL.

\section{Introduction}

Paravertebral and ligamentous ossification appears to be an unusual complication of hypoparathyroidism. The association has been reported in idiopathic and post-operative hypoparathyroidism (Büscher, 1948; Salvesen and Böe, 1953; Gibberd, 1965; Chaykin, Frame and Sigler, 1969).

The clinical, biochemical and radiological features of another case are described and the differential diagnosis is discussed. 


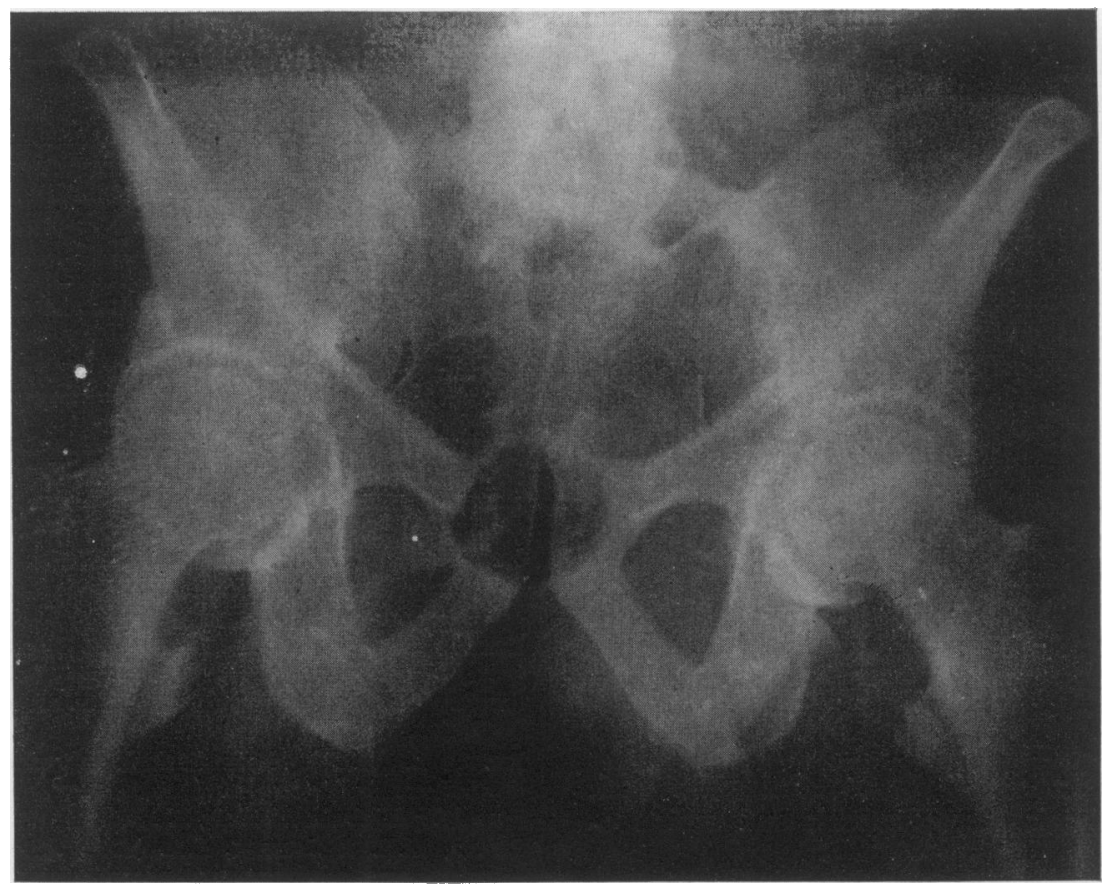

Fig. 1. Pelvis, showing ligamentous and tendinous ossification and calcification of the capsules of the hip joints. The sacroiliac joints are normal.

\section{Case history}

The patient, a 62-year-old man, was initially referred to the Manchester Royal Eye Hospital in June 1974 with a 6-week history of failing vision. He was found to have bilateral cataracts and diabetes mellitus and subsequently shown to have hypocalcaemia. He was transferred to the Metabolic Unit at the Royal Infirmary for further investigation and treatment.

He was not a good historian but did describe an illness, when he was 18 years old, in which he experienced facial paraesthesiae associated with rigidity and flexion of his hands and feet. This illness, which lasted for about 39 weeks, eventually resolved and has not recurred. In 1952 he began to experience pain and stiffness in his back, neck, hips, elbows and shoulders. These symptoms have persisted and become progressively worse over the years, resulting in his premature retirement from the coal mining industry at the age of 57 years. There was no past history of epilepsy, bowel disturbance, or pain and swelling in the wrists, hands or feet. He had always been small of stature and smaller than his parents and siblings. There was no relevant family history.

\section{Physical findings}

He was short and slightly obese (height, $147 \mathrm{~cm}$; weight, $63 \mathrm{~kg}$ ) and had a forward stoop of the trunk.

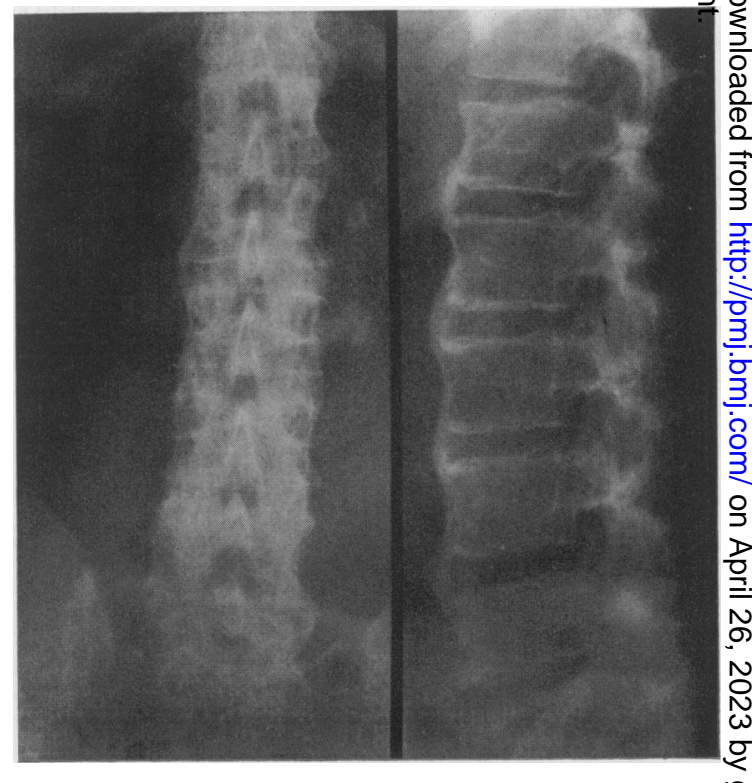

Fig. 2. Lumbar spine with ossification anterior to the vertebral bodies and in the ilio-lumbar ligaments.

The spinal column was immobile apart from slight $\frac{7}{0}$ flexion and extension at the thoraco-lumbar junc- $\frac{\text { Dे }}{\mathbb{D}}$ tion. There was $15^{\circ}$ of skull rotation. The small $\underset{\mathbb{D}}{\stackrel{\odot}{\circ}}$ 


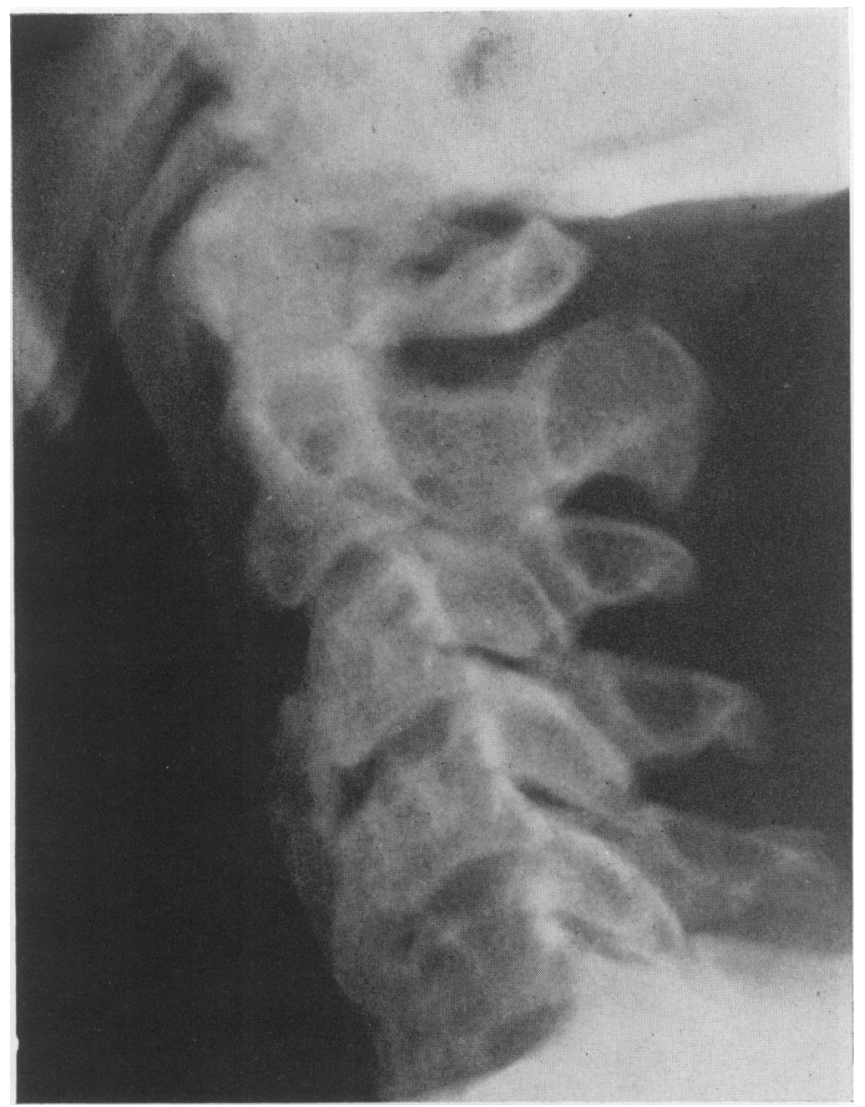

FIg. 3. Cervical spine with plaques of ossification lying anterior to the vertebral bodies.

joints of the hands and feet appeared normal. Flexion and extension of the wrists were reduced, there were $10^{\circ}$ flexion deformities at the elbows with limitation of supination and pronation of both forearms. Shoulder abduction was limited to $90^{\circ}$. Movements at the hip joints were absent apart from flexion, which was limited to $45^{\circ}$. There was no skin rash but some nails were dystrophic. There was neither overt nor latent tetany. There were bilateral posterior subcapsular cataracts. Examination of the nervous system was normal and there was no muscle weakness.

\section{Investigations}

The urine contained $2 \%$ glucose and a random blood sugar was $330 \mathrm{mg} / 100 \mathrm{ml}$. Haemoglobulin was $12 \cdot 1 \mathrm{~g} / 100 \mathrm{ml}$; leucocyte count $5700 / \mathrm{mm}^{3}$; ESR varied between 50 and $90 \mathrm{~mm} / \mathrm{hr}$ (Westergren). Total serum protein was $7 \cdot 3 \mathrm{~g} / 100 \mathrm{ml}$ (albumin $4.0 \mathrm{~g} / 100 \mathrm{ml}$ ); the electrophoretic pattern showed a slight increase in $\alpha_{2}$ globulins. Sternal marrow showed normal erythropoiesis. Antinuclear factor, rheumatoid factor, gastric parietal cell and thyroid antibodies were not present. HLA antigens 2, W18 and W21 were identified. Daily faecal fat excretion was $3.2 \mathrm{~g}$ (normal). Candida albicans was not grown from the faeces or nail scrapings. Plasma 11-hydroxycorticosteroid concentration was normal with a normal diurnal variation. Serum calcium was 5.9 $\mathrm{mg} / 100 \mathrm{ml}$; inorganic phosphorus $4.3 \mathrm{mg} / 100 \mathrm{ml}$; magnesium $1.26 \mathrm{mg} / 100 \mathrm{ml}$ and creatinine $1.2 \mathrm{mg}$ / $100 \mathrm{ml}$. No immunoassayable parathyroid hormone could be detected in the serum. The serum phosphorus concentration decreased and there was a phosphaturia in response to an intravenous infusion of parathyroid extract. These findings confirm the diagnosis of idiopathic hypoparathyroidism.

\section{Radiology}

Where the radiological appearances suggest new bone formation the term 'ossification' is used. However, where doubt exists the extra-osseous changes are described as 'calcification'.

Radiographs of the skull show calcification in the 


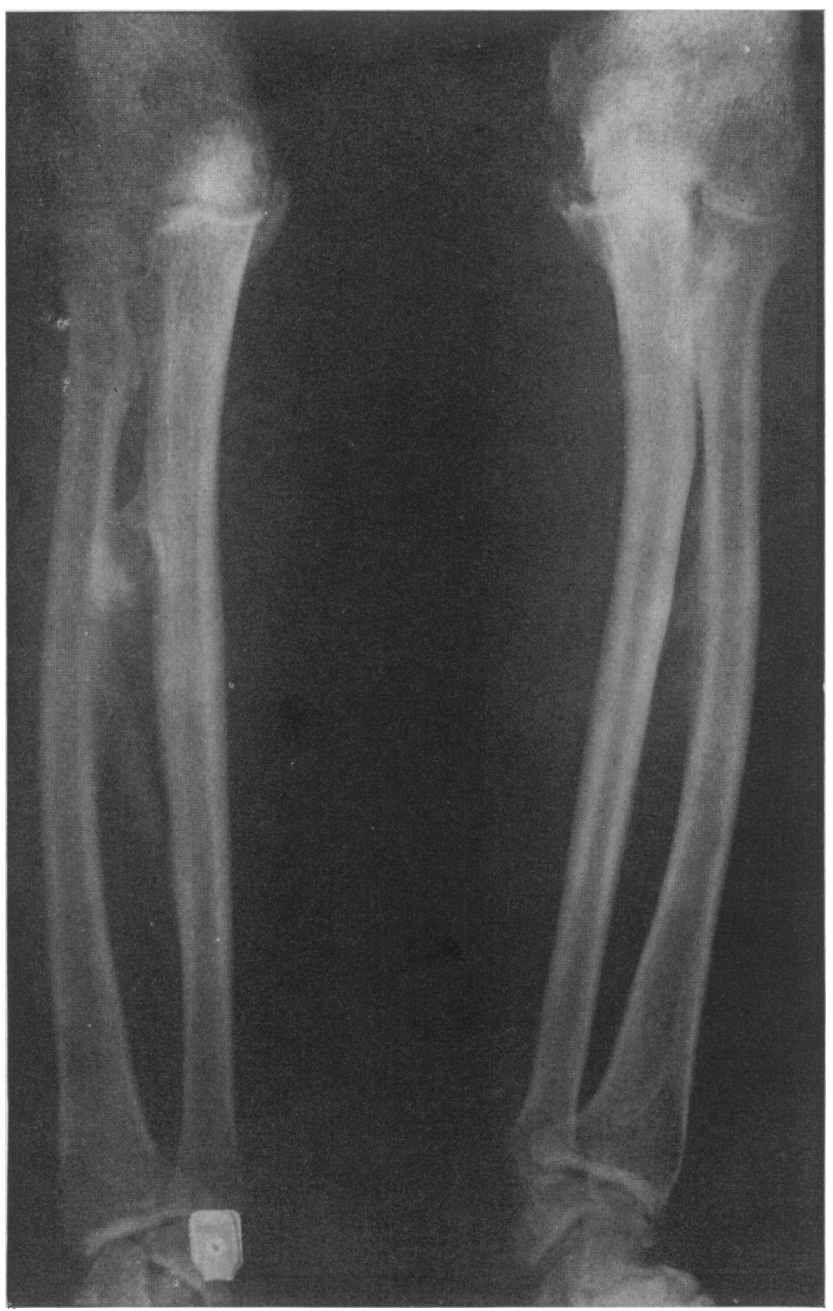

Fig. 4. Forearms showing ossification around the elbow joints, in the interosseous membrane and synostosis of the right radius and ulna.

basal ganglia. In the pelvis there was ossification of the sacro-spinous, sacro-tuberous and iliolumbar ligaments resulting in fixed anterior tilting of the pelvis. Similar changes were present in the psoas insertions of the lesser trochanters. Calcification was present in the capsules of both hip joints, in the gluteal insertions of the iliac crests and along the ischial tuberosities (Fig. 1).

There was almost complete ankylosis of the spine. In the lumbar region this was due to ossification, up to $5 \mathrm{~mm}$ in depth, lying primarily anterior to the vertebral bodies (Fig. 2). Similar changes were present in the cervical spine where the plaques of ossification lying anterior to the bodies of $\mathrm{C} 3$ to $\mathrm{C} 7$ measured up to $1 \mathrm{~cm}$ in depth (Fig. 3).
In contrast, no anterior ossification was present in the thoracic spine. Here, and in the upper lumbaro region, there were bony flanges of both the 'marginal'? and 'other-than marginal' types (McEwan et al., 1971), these being more extensive on the left side The flanges of 'other-than marginal' types predominated. The sacro-iliac and apophyseal joints 0 were normal. The intervertebral disc spaces were preserved. There was 'wedging of the body of T120 which was the only site of movement of the thoracos lumbar spine. Ossification was present in the interos $\frac{\bar{D}}{\mathrm{D}}$ seous membranes of the forearms resulting in ${ }^{?}$ synostosis of the right radius and ulna (Fig. 4).0 Ossification was present in the triceps insertions? and medial ligaments of both elbows, the lef? 
patella ligament and the left Achilles tendon. There was calcification in the capsules of the shoulder joints and in the coracoclavicular ligaments. Vascular calcification and small bilateral calcaneal spurs were noted in the feet. Growth arrest lines were present in the upper ends of the tibiae and fibulae.

\section{Discussion}

Several patients with idiopathic hypoparathyroidism and extensive paravertebral and ligamentous calcification have been described.

Büscher (1948) reported a 43-year-old woman with hypoparathyroidism following thyroid surgery 12 years previously. She complained of pain in the back, hips, knees and shoulders. Radiographs showed calcification of the ilio-sacral ligaments and periosteal new bone formation along the pubic rami and ischial tuberosities. Calcified spicules arose from the edges of the vertebral bodies, particularly in the thoraco-lumbar region, and from the acetabular margins. Similar changes were present in the shoulder joints.

Salvesen and Böe (1953) described a 57-year-old man who presented with a 16-year history of progressive but painless stiffness affecting the back and hips. Movements of the back were found to be limited in all directions and there was severe restriction of movements at the hip joints. He was known to have had idiopathic hypoparathyroidism for several years, having been treated with vitamin $D$ and oral calcium supplements. Radiographs showed ossification of the anterior longitudinal ligament in the upper and lower parts of the spine and in some of the 'lateral ligaments'. There was irregular new bone formation around the bones of the pelvis; marked calcification of the sacro-tuberous ligaments and in the capsule of the hip joints. The sacro-iliac joints were normal.

Gibberd (1965) described a woman of 29 years of age who presented with stiffness in the legs and difficulty in walking. She was found to have a spastic paraparesis but in addition was noted to have marked limitation of movements of the spine and of both hips. She was shown to have idiopathic hypoparathyroidism. Radiographs showed ossification of the ligaments of the lumbar spine; and new bone formation at the acetabular rims, the ischial tuberosities and the right anterior iliac spine. The sacro-iliac joints were normal.

Chaykin et al. (1969) described a man, who presented when he was 59 years old, with a 10-year history of progressive stiffness and pain affecting the back and hips. There was gross limitation of movement of the cervical, thoracic and lumbar spine and his gait and posture resembled those seen in patients with ankylosing spondylitis. Movements at the hips and shoulders were also restricted but the other peripheral joints in the arms and legs were normal. He was shown to have idiopathic hypoparathyroidism. Radiographs of the spinal column showed extensive calcification of paraspinal ligaments, prominent fused osteophytes arising from the anterior aspect of the cervical spine and calcification of the apophyseal articulations. There was irregular new bone formation on the lateral walls of the pelvis and calcification of the coraco-acromial ligament and the annulus of the glenoid. The sacro-iliac joints were normal.

These four cases have features resembling those in the present patient. All had hypoparathyroidism with paravertebral and ligamentous ossification but normal sacro-iliac joints. Evidence of an erosive arthropathy or any disease known to be associated with ligamentous ossification was lacking.

Two other cases of hypoparathyroidism with paravertebral calcification have been described but, in both, other conditions were present which may have accounted for this finding. Ott and Stepan (1967) reported a 50-year-old woman with postthyroidectomy hypoparathyroidism who was found to have new bone formation around the pelvis, ossification of the spinal ligaments and sacro-iliitis. This patient probably had ankylosing spondylitis. Gsell (1950) reported a woman with hypoparathyroidism and calcification of the spinal ligaments but, in addition, she had psoriasis.

Other authors have commented upon calcification of tendon insertions in patients with hypoparathyroidism (Steinberg and Waldron, 1952; de Mowbray, Llewellyn Smith and Symonds, 1954; Dimich, Bedrossian and Wallach, 1967; Simpson, 1952).

The patient here described and those reported by Büscher (1948), Salvesen and Böe (1953), Gibberd (1965) and Chaykin et al. (1969) had symptoms and clinical signs which closely resembled those found in patients with ankylosing spondylitis. In addition, all had marked limitation of movement of hip and shoulder joints but without evidence of arthritis affecting the small joints. All the patients shared similar radiological features which were different from those of ankylosing spondylitis and other types of spinal hyperostoses and spondylitides. In the present patient most of the abnormalities appeared radiologically to be the result of new bone formation in the para-vertebral region, ligaments and tendons. In some places, particularly along the iliac crests and in the capsules of the hip joints, no bony trabeculae could be seen within the abnormal calcification. These may have been sites of simple soft tissue calcification rather than ossification, though it is not possible to be certain of this without histological evidence. The absence of a sacro-iliitis excludes the 
diagnosis of ankylosing spondylitis. In this context the failure to identify tissue antigen HLA 27 in the present patient is of interest (Brewerton et al., 1973).

The ossification in ankylosing spondylitis involves primarily the outer fibres of the annulus of the disc, forming marginal syndesmophytes. The authors describe bony flanges, including those of 'other-than marginal' type, which McEwan et al. (1971) found to be rare in ankylosing spondylitis, but were present in patients with psoriasis and Reiter's disease. Bywaters and Dixon (1965) described the paravertebral calcification which may occur in association with psoriasis as a band of new bone lying lateral to the vertebral bodies and separated from them by an interval. In the patient described here, some of the paravertebral calcification was of this type. The changes present in the cervical and thoracic spine of the patient were similar to those found in senile spinal hyperostosis (Forestier and Rotes-Querol, 1950). This is reported to occur with higher frequency in association with diabetes mellitus(Hajkova, Streda and Skrha, 1965). The patient here described had maturity-onset diabetes mellitus and this may have been a contributory factor, but cannot account for all the extra-osseous calcification and ossification which was present.

Paravertebral ossification is recognized as occurring in ankylosing spondylitis and in some patients with Crohn's disease, Reiter's disease, ulcerative colitis, psoriasis, familial hypophosphataemic (vitamin $D$ resistant) osteomalacia, fluorosis, diabetes mellitus, and the elderly. All these conditions have distinctive clinical, biochemical and radiological features which allow their differentiation. The distinctive radiological features in hypoparathyroidism are the extensive peripheral ligamentous calcification and the absence of an erosive arthropathy or sacro-iliitis.

Chaykin et al. (1969) have discussed possible reasons for the paravertebral and soft tissue calcification found in patients with hypoparathyroidism. At present, the responsible mechanism is, as is that causing the calcification of the basal ganglia, unknown; but it may be related as much to the chronicity of the disorder as to the severity of the hypocalcaemia and hyperphosphataemia.

\section{Acknowledgments}

We wish to thank Dr D. Davies for referring the patien Professor S. W. Stanbury for permission to publish this case report and the Department of Medical Illustration, Man: chester Royal Infirmary. This work was supported, in parf by a grant to Professor Stanbury from the M.R.C. and D.H.S.S.

\section{References}

Brewerton, D.A., Hart, F.D., Nicholls, A., Caffrey, $\mathbf{M}_{\mathscr{\Phi}}^{\mathbb{\Phi}}$ JAmes, D.C.O. \& Sturrock, R.D. (1973) Ankylosing spondylitis and HLA 27. Lancet, i, 904.

BüsCHER, VON B. (1948) Osteoarthropathia parathyreoiprivid scleroticans. Röntgenpraxis, 17, 252.

Bywaters, E.G.L. \& Dixon, A.ST.J. (1965) Paravertebr $\overrightarrow{\mathrm{b}}$ ossification in psoriatic arthritis. Annals of the Rheumat: Diseases, 24, 313.

Chaykin, L.B., Frame, B. \& Sigler, J.W. (1969) Spondylitisĭ. a clue to hypoparathyroidism. Annals of Internal Mediciner 70, 995 .

De Mowbray, R.R., Llewellyn Smith, S.H. \& Symonds W.L.C. (1954) Hypoparathyroidism and pseudohypoparathyroidism. British Medical Journal, 1, 903.

Dimich, A., Bedrossian, P.B. \& Wallach, S. (1957) Hypoparathyroidism-clinical observations in 34 patients Archives of Internal Medicine, 120, 449.

Forestier, J. \& Rotes-Querol, J. (1950) Senile ankylosin hyperostosis of the spine. Annals of the Rheumatic Disease 321 .
(5)

GiBBERD, F.B. (1965) Idiopathic hypoparathyroidism with unusual bone changes and spastic parapleglia. endrocrinologica, 48, 23.

Gsell, O. (1950) Chronische idiopathische Tetanie Psoriasis) (hypoparathyreoider Kretinismus). Deutsen medizinisches Wochenschrift, 75, 1117.

Hajkova, Z., Streda, A. \& Skhra, F. (1965) Hyperostoti spondylitis and diabetes mellitus. Annals of the Rheumatio Diseases, 24, 536.

McEwan, C., Ditata, D., Lingg, C., Porini, A., Good, A $\overrightarrow{\bar{\sigma}}$ \& RANKIN, T. (1971) Ankylosing spondylitis and spondy litis accompanying ulcerative colitis, regional enteritis, psoriasis and Reiter's disease. Arthritis and Rheumatism 14, 291.

OTT, V.R. \& STEPAN, J. (1967) Spondylitis ankylopoietic bei postoperative Hypoparathyreose und Hypothyreose Zeitschrift für Rheumaforschung, 26, 20.

SAlvesen, H.A. \& BöE, J. (1953) Idiopathic hypopara thyroidism. Acta endocrinologica, 14, 214.

Simpson, J.A. (1952) The neurological manifestations ot idiopathic hypoparathyroidism. Brain, 75, 76.

SteinberG, H. \& Waldron, R.R. (1952) Idiopathic hypo? parathyroidism: an analysis of fifty-two cases includin the report of a new case. Medicine. Baltimore, 31, 133. 